\title{
Analysis and optimization of different two-stage transcritical carbon dioxide cycles for heating applications
}

\author{
M. PITARCH ${ }^{(a)}$, E. NAVARRO-PERIS ${ }^{(a)}$, J. GONZALVEZ(a), JM. CORBERAN ${ }^{(a)}$ \\ (a) Instituto de Ingeniería Energética, Universitat Politècnica de València, Camí de Vera s/n, \\ Valencia, 46022, Spain \\ Tel: +34 963879123 \\ enava@ter.upv.es
}

\section{Abstract}

Increased interest in the environmental impact of refrigeration technology is leading toward design solutions aimed at improving the energy efficiency and use of eco-friendly refrigerants with low GWP. The aim of this paper is to theoretically analyse R744 air to water heat pump cycles for heating applications up to $80{ }^{\circ} \mathrm{C}$. This work studies the following cycle configurations: two-stage with injection (with and without intermediated cooling between compressors) and a single-stage circuit coupled with an auxiliary circuit. Internal heat transfer among the different streams of refrigerant is included, and the cycles have been optimized with regards to COP in terms of the intermediate conditions and gas cooler pressure. Finally, these cycles have been compared and analysed among each other and with a subcritical injection cycle working with R134a and a single-stage R744 cycle. The improved cycle with R744 can represent a global improvement of $15 \%$ in terms of COP.

Keywords : R744, heat pumps, natural refrigerants, two-stage systems, optimization

The original paper was presented at the 11th IIR Gustav Lorentzen Conference on Natural Refrigerants (GL2014), 31 Aug. to 2 Sept. 2014, Hangzhou, China. 


\section{NOMENCLATURE}

ACC: Auxiliary compressor cycle

$\mathrm{C}_{0}$ : Coefficient of geometric mean of pressures, [-]

$\mathrm{COP}_{\mathrm{h}}$ : Heating COP, [-]

$\dot{E}$ : Power consumption of compressor, $[\mathrm{kW}]$

EU: European Union

GWP: Global warming potential

HCFCs: Hydrochlorofluorocarbons

HFCs: Hydrofluorocarbons

HFOs: Hydrofluoroolefins

HP: High pressure

HPAHX: High pressure auxiliary heat exchanger

HPIHX: High pressure internal heat exchanger

$h_{A x x}$ : Enthalpy at point xx, cycle ACC, [ $\left.\mathrm{kJ} \mathrm{kg}^{-1}\right]$

$h_{i}$ : Enthalpy at the compressor inlet, [ $\left.\mathrm{kJ} \mathrm{kg}^{-1}\right]$

$h_{o}$ : Enthalpy at the compressor outlet, [ $\left.\mathrm{kJ} \mathrm{kg}^{-1}\right]$

$h_{o s}$ : Isentropic Enthalpy at the compressor outlet, [ $\left.\mathrm{kJ} \mathrm{kg}^{-1}\right]$

$h_{T x x}$ : Enthalpy at point xx, cycle TSCC, [kJ kg-1]

ICHX: Inter-cooling heat exchanger

IHX: Internal heat exchanger

LP: Low pressure

$\dot{m}_{c}$ : Refrigerant mass flow through compressor, $\left[\mathrm{kg} \mathrm{s}^{-1}\right]$

$\dot{m}_{a u x}$ : Refrigerant flow through auxiliary compressor, $\left[\mathrm{kg} \mathrm{s}^{-1}\right]$

$\dot{m}_{e v}$ : Refrigerant flow through evaporator, [ $\left.\mathrm{kg} \mathrm{s}^{-1}\right]$

$\dot{m}_{g c}$ : Refrigerant mass flow through gas cooler, $\left[\mathrm{kg} \mathrm{s}^{-1}\right]$

$\dot{m}_{i n j}$ : Refrigerant flow through injection, [kg s$\left.{ }^{-1}\right]$

$\mathrm{P}_{\mathrm{C}}$ : Pressure at the gas cooler, [bar]

$\mathrm{P}_{\mathrm{ev}}$ : Pressure at the evaporator, [bar] 
$\mathrm{P}_{\text {int: }}$ Intermediate or auxiliary pressure, [bar]

$\mathrm{Q}_{\mathrm{h}}$ : Heating capacity, [kW]

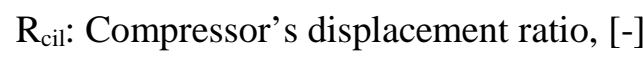

rp: Pressure ratio, [-]

sh: Super Heat, [K]

SPF: Seasonal Performance Factor

TEWI: Total equivalent warming impact

TSCC: Two-stage compression cycle

$\mathrm{T}_{\mathrm{ev}}$ : Evaporating temperature, $\left[{ }^{\circ} \mathrm{C}\right]$

$\mathrm{T}_{\text {disch: }}$ Discharge temperature, $\left[{ }^{\circ} \mathrm{C}\right]$

$\mathrm{T}_{\mathrm{HP} \_ \text {stage: }}$ Temperature at high-pressure stage compressor, $\left[{ }^{\circ} \mathrm{C}\right]$

$T_{T x x}$ : Temperature at point xx, cycle TSCC, $\left[{ }^{\circ} \mathrm{C}\right]$

$\mathrm{x}_{\mathrm{inj}}$ : Injection and Auxiliary Ratio, [-]

$\eta_{v}:$ Volumetric compressor efficiency, [-]

$\eta_{b}$ : Compressor efficiency, [-]

\section{INTRODUCTION}

Heat pumps constitute an efficient mechanism of producing heating and cooling for the building sector. Due to this fact, the European Union (EU) promotes their use for domestic heating applications rather than other possible alternatives, especially when the operating temperature gap between the hot and the cold side of the heat pump is not very high.

Nevertheless, facts like most used refrigerants nowadays having a high global warming potential (GWP) and the efficiency and capacity dropping when heat pumps work at a high temperature difference between hot and cold side are issues that should be still addressed. The first point is pushing the EU to approve new regulations (517/2014) in order to limit the use of hydrofluorocarbons (HFCs) and give support to other refrigerants with less GWP, like some natural refrigerants. 
Regarding the performance reduction of heat pumps at high temperature differences, several alternatives are being applied nowadays in order to overcome this effect, for instance, the use of geothermal systems in cold climates (Self et al. 2013), the implementation of more complex vapour compression systems (Xu et al. 2011) and, for heating applications, the use of a vapour compression system working in transcritical conditions using $\mathrm{CO}_{2}$ as a refrigerant (Austin et al. 2011, Groll and Kim, 2007).

Derived from the necessity of finding a clean alternative to HCFCs and HFCs, $\mathrm{CO}_{2}$ has recovered interest in the last decades, and its applications working in transcritical cycles are expanding (Lorentzen 1994, Lorentzen and Pettersen, 1993). Refrigeration systems for supermarkets are nowadays implementing this solution (Samer 2008), part of the automotive industry is promoting its development for vehicles and, for the residential sector, the use of $\mathrm{CO}_{2}$ transcritical systems has shown good performance as a substitute for boilers for the production of sanitary hot water using heat pumps (Cecchinato et al. 2005).

The use of heat pumps for the production of sanitary hot water has some differences compared to the use of heat pumps for air conditioning; the final water temperature is quite high $\left(60^{\circ} \mathrm{C}\right)$, and the water temperature lift is large $\left(50^{\circ} \mathrm{C}\right)$, i.e. the difference between the water temperature inlet and outlet in the hot side is high. These two facts make that the use of $\mathrm{CO}_{2}$ in transcritical conditions have some technical advantages beyond environmental arguments in comparison to the use of HFCs, particularly in terms of the R134a equipment available in the market (Bowers et al. 2013, Pitarch et al. 2014, Sarkar 2012).

There are some heating installations in the EU equipped with old radiators, which require the supply of water at temperatures of $70-80^{\circ} \mathrm{C}$. In most of these cases, the hot water production is made using a boiler, and the possibilities of implementing heat pump technologies in these old systems are quite restricted. Based on the experience obtained with the applications of heat pumps to produce sanitary hot water using $\mathrm{CO}_{2}$ as a refrigerant, the extension of this kind of technology to this kind of application can be suitable as these systems present a high temperature lift $\left(40{ }^{\circ} \mathrm{C}\right)$ and the water temperature is high. However, as a consequence of the high water temperature and in order to enhance the efficiency of the system, some modification to the vapour 
compression system, like working in two-stage cycles, should be analysed. These cycles and its optimization have been analysed theoretically in the literature but not in these specific conditions (Agrawal et al. 2007, Cho et al. 2009, Srinivasan 2011).

In this frame the EU has founded the development of a set of five safe, reliable, high efficiency and high capacity heat pumps working with natural refrigerants and the development of a set of improved components and auxiliary devices adequate for their efficient and safe use. The selected refrigerants are propane and $\mathrm{CO}_{2}$. The objective also includes providing the necessary know-how to key European companies in the sector to bring to the market the developed technology and to find new applications in which this technology could be of interest. The project aims at reaching higher efficiency (10-20\% SPF improvement) and a lower carbon footprint (20\% TEWI reduction) than current state of the art HFCs/HFOs.

One of the selected prototypes consists of the design of an air to water heat pump dedicated to the production of hot water at temperatures of $80^{\circ} \mathrm{C}$ using $\mathrm{CO}_{2}$ as a refrigerant from a water source of $40{ }^{\circ} \mathrm{C}$ (nominal conditions) in order to substitute for boilers in old heating installations. Based on the possible market for this kind of heat pump in Europe, a capacity of $30 \mathrm{~kW}$ has been selected. In the first part of the project, COP will not be a major issue as there is no reference heat pump in the market for this kind of application.

In this work, the initial theoretical study about the performance of the different possible configurations of the system has been developed. Due to the high water temperature in this kind of application, a two-stage configuration system was selected. Cecchinato et al. (2009) performed an extensive theoretical study about several two-stage systems but for other working conditions. Based on the adaptation of this analysis for our specific system, and, following the recommendations of the manufactures in the consortium, the following configurations have been considered: two-stage with injection (with and without intermediated cooling between the two compression stages) and a single-stage circuit coupled with an auxiliary subcooling circuit. A detailed analysis of the different advantages of each cycle has been obtained. The analysis includes the evaluation of the influence of external conditions, the optimization of COP of each cycle as a function of the intermediate conditions and gas cooler pressure, a comparison with a one-stage $\mathrm{CO}_{2}$ cycle and a two-stage 
R134a cycle used for the same application and an analysis of the best strategy in case the compressor discharge temperature must be reduced.

\section{CYCLES UNDER ANALYSIS}

The present study investigated the performance of different transcritical thermodynamic cycles working with $\mathrm{CO}_{2}$, from a theoretical point of view by means of the commercial software EES (F-Chart Software). The different cycles investigated in the present study are presented below:

- Two-stage compression cycle (TSCC), Figures 1a and b. Two compressors work in series. The mass flow splits right after the gas cooler; one part will expand at the injection-throttling valve (point 11) and interact with the mass flow rate going to the evaporator (point 6) in the "High Pressure Internal Heat exchanger”(HPIHX). The superheat at the low stage compressor (point 1) is reached with the liquid to suction exchanger (IHX). In order to reduce the discharge temperature of the high pressure compressor, two possibilities are considered:

After the low-pressure stage, the refrigerant can be cooled down with the Inter-Cooling Heat exchanger (ICHX). This heat exchanger is located right after the low pressure compressor, and it exchange heat with the ambient, hence the heat rejection will depend on the ambient temperature. One should notice that a superheat of $5 \mathrm{~K}$ is maintained at the outlet of HPIHX (point 13), which will mix with the refrigerant mass flow coming from the ICHX.

The throttling valve is controlled in order to control directly the superheat at the entrance of the high-pressure stage (point 4). In this case, ICHX is not used.

- Auxiliary Compressor cycle (ACC), Figures 2a and b. Two compressors work in parallel. The main compressor works between the evaporating and gas cooler pressure while the auxiliary compressor works between an intermediate pressure and gas cooler pressure. The two mass flow rates merge before the gas cooler (point 3) and split again right at the outlet (point 4); one part passes through the throttling 
valve (point 7) that feeds the auxiliary compressor and then interacts in the High Pressure Auxiliary Heat exchanger (HPAHX) with the mass flow that goes to the evaporator.

The obtained results have been compared with a single-stage $\mathrm{CO}_{2}$ cycle and a two-stage subcritical cycle working with R134a.

\section{MATHEMATICAL MODELING}

The following parameters are kept constant for all the cases: $5 \mathrm{~K}$ of superheat at the inlet of the low pressure compressor for cycle TSCC; $5 \mathrm{~K}$ of superheat for the main and auxiliary compressor for cycle ACC. The gas cooler has a temperature approach of $5 \mathrm{~K}$ at its outlet, assuming that the water enters with a temperature of 40 ${ }^{\circ} \mathrm{C}$. For the external conditions, two different evaporating temperatures were analysed, -15 and $0{ }^{\circ} \mathrm{C}$.

Pressure drop in pipes and heat exchangers as well as heat losses are considered to be negligible. All expansion devices have an isenthalpic expansion.

Regarding the compressor, according the information from the manufacturer, volumetric efficiency follows a polynomial relation with the pressure ratio (Eq. (1)), and compressor efficiency was maintained constant at a value of 0.66, which is a reasonable approach for the used piston compressor. Furthermore, the heat losses are assumed to be $4 \%$ of the compressor consumption, Eq. (2).

$$
\begin{gathered}
\eta_{v}=0.0089 \cdot r p^{2}-0.1508 \cdot r p+1.1254 \\
\eta_{b}=\frac{\dot{m}_{c}\left(h_{o s}-h_{i}\right)}{\dot{E}}=\frac{\dot{m}_{c}\left(h_{o s}-h_{i}\right)}{\dot{m}_{c}\left(h_{o}-h_{i}\right)+0.04 \cdot \dot{E}}=0.66
\end{gathered}
$$


The size for main compressor in ACC and for the first stage in TSCC is fixed to a $7\left[\mathrm{~m}^{3} \mathrm{~h}^{-1}\right]$ of displacement, while the size of the second stage (auxiliary for ACC) compressor is determined in the first part of the study in order to work in the optimum COP condition.

\subsection{Two-stage compression cycle (TSCC)}

In the TSCC cycle the first stage compressor superheat is kept to $5 \mathrm{~K}$, while the inlet conditions on the second stage (point 4) will depend on the mixing refrigerant from injection and first stage compressor, Eq. (3)

$$
\dot{m}_{g c} \cdot h_{T 4}=\dot{m}_{i n j} \cdot h_{T 13}+\dot{m}_{e v} \cdot h_{T 3} \quad ; \text { If ICHX is not used } \rightarrow h_{T 3}=h_{T 2}
$$

One should notice that when the ICHX is working, the enthalpy at its outlet will depend on the conditions of the external cooling agent, for example the ambient temperature, in this case superheat at point 13 is maintained to $5 \mathrm{~K}$. Different degrees of refrigerant cooling has been under study. On the other hand, when ICHX is not used, the temperature at point 4 is given and the enthalpy at point 13 will depend on it.

The energy balance at the HPIHX is given by

$$
\dot{m}_{e v}\left(h_{T 6}-h_{T 7}\right)=\dot{m}_{i n j}\left(h_{T 13}-h_{T 12}\right)
$$

In the equation above, two condition must be fulfilled

$$
\text { Conditions HPIHX }\left\{\begin{array}{c}
T_{T 13}<T_{T 6} \\
T_{T 7}=T_{T 12}+5
\end{array}\right.
$$

Refrigerant at the evaporator outlet is in vapour saturated state, and the necessary superheat before entering to the compressor is given by IHX, a $5 \mathrm{~K}$ superheat is considered.

\subsection{Auxiliary compressor cycle (ACC)}

The conditions at the inlet of the gas cooler will depend on the merged refrigerant flows coming from the main and auxiliary compressor, Eq. (6) 


$$
\dot{m}_{g c} \cdot h_{A 3}=\dot{m}_{e v} \cdot h_{A 2}+\dot{m}_{a u x} \cdot h_{A 9}
$$

Right after the gas cooler, the refrigerant flow splits into the mass flow going to the main compressor and the one going to the auxiliary compressor. Both flows interact in the HPAHX, which acts as an evaporator for the auxiliary refrigerant flow. The energy balance at the HPAHX is expressed by

$$
\dot{m}_{a u x}\left(h_{A 8}-h_{A 7}\right)=\dot{m}_{e v}\left(h_{A 4}-h_{A 5}\right)
$$

Superheat for both compressors is taken $5 \mathrm{~K}$ unless another it is specified.

\section{RESULTS}

The cycles described in the previous section have been modelled, and, in order to compare their relative behaviour, a parametric study on the function of the intermediate conditions and the gas cooler pressure has been developed for external conditions corresponding to $0{ }^{\circ} \mathrm{C}$ and $-15{ }^{\circ} \mathrm{C}$ of evaporating temperature. The parameters under study are COP of the system and discharge temperatures, since too high values of the second parameter could limit the operational range of the system.

Regarding to the intermediate conditions, it has been used a coefficient $\mathrm{C}_{0}$, which relates the intermediate (auxiliary for ACC) pressure with the geometric mean of the evaporator and gas cooler pressures. The selection of $\mathrm{C}_{\mathrm{O}}$ in order to represent the values of the intermediate conditions has been motivated by the fact that the optimum intermediate pressure should be closer to the mean geometric pressure, and, in this way, the numerical value of the intermediate optimum pressure is expressed as a variable whose absolute value does not depend on the used refrigerant. One should notice that changing $\mathrm{C}_{\mathrm{o}}$ when the other parameters are kept constant, such as superheat, is equivalent to change the size of the second stage compressor.

$$
P_{\text {int }}=C_{O} \sqrt{P_{e v} P_{C}}
$$


Figure 3 represents the results obtained for cycle TSCC without ICHX compared with ACC for the nominal evaporating temperature of $0^{\circ} \mathrm{C}$. Figures $3 \mathrm{a}$ and $3 \mathrm{c}$ represent the heating $\mathrm{COP}$ of the system depending on the pressure at the gas cooler and the coefficient $\mathrm{C}_{0}$. They show that both cycles have a similar COP distribution with a slightly higher maximum for ACC. Figures 3b and 3d show the highest refrigerant temperature for each cycle. For cycle TSCC this temperature is at the entrance of the gas cooler, while in the ACC cycle the highest temperature corresponds to the discharge of main compressor. Temperatures at the ACC cycle are higher than TSCC, and they do not depend on the intermediate conditions, it increase as the gas cooler pressure increases, on the other hand temperatures for TSCC depend on gas cooler pressure and intermediate conditions $\left(\mathrm{C}_{\mathrm{O}}\right)$ at the same time.

Once the optimum condition for the gas cooler pressure is defined, the displacement volume ratio of the used compressors can be selected in order to implement these kind of systems. Figure 4 shows COP variation with the displacement ratio for both systems. It can be seen that TSCC has its optimum with a displacement ratio of approximately 0.95 while ACC must have an auxiliary compressor 0.25 the size of the main compressor in order to reach the optimum in these conditions. Looking at the slopes of the curves, it can be seen that the ACC cycle has a major COP penalty when the compressor volumes are selected wrongly.

Table 1 shows the results for different systems working at its optimum point. Comparing the capacities of both systems, TSCC has a higher heating capacity than ACC. This effect is derived from the different compressor's position, in the ACC system the main compressor works with a higher pressure ratio than the first stage compressor in TSCC, thus the volumetric efficiency is higher in the TSCC system and has a higher refrigerant mass flow consequently. Comparing TSCC and ACC with a one-stage compressor $\mathrm{CO}_{2}$ system and a twostage R134a cycle, there is an improvement in the heating COP of about 11 and 14 per cent respectively, which supports the selection of this kind of refrigerant for this application in addition to environmental motivations.

Once the second stage is optimized for the nominal evaporating condition, the displacement is fixed, and the performance of the system is studied at an evaporating temperature of $-15^{\circ} \mathrm{C}$ (Table 1 ). In this case, the heating COP is reduced around 18 per cent for both cycles. The discharge temperature at the high-pressure stage in the TSCC cycle is about $110^{\circ} \mathrm{C}$, whereas it is about $133^{\circ} \mathrm{C}$ for the ACC cycle. 
Therefore, due to the high temperatures reached at the outlet of the main compressor, it could be inappropriate to use the ACC cycle between these operational conditions. This is even more evident for the single-stage compressor, where the heating COP is reduced about 18.5 per cent and the discharge temperature is $147^{\circ} \mathrm{C}$, which is outside the oil reliability limit for the compressor. The two-stage compressor working with the subcritical refrigerant $\mathrm{R} 134 \mathrm{a}$ has a similar heating $\mathrm{COP}$ as the single $\mathrm{CO}_{2}$ cycle, but the discharge temperature is about $115^{\circ} \mathrm{C}$ (table 1); therefore, this refrigerant could work under this condition, but the reduction in COP compared with $\mathrm{CO}_{2}$ is important. In some of these conditions, the compressor discharge temperature could be an issue for these kind of cycles (usually it cannot be higher than $150{ }^{\circ} \mathrm{C}$ ); hence, the analysis of the possible alternatives to reduce the discharge temperature of this cycle has to be studied.

TSCC can reduce the discharge temperature in two ways:

- The refrigerant coming out of the low-pressure stage is cooled down by means of a heat exchanger (ICHX). The heat is rejected to the ambient, so the temperature is reduced before the mixing point with the injection mass flow.

- The throttling valve is controlled in order to obtain a certain degree of superheat at the inlet of the high-pressure stage (point 4). In this case, ICHX is not working and the quality of the refrigerant at the outlet of HPIHX (point 13) can be below 1.

Figure 5a shows the heating COP of the TSCC system for different intermediate superheats (point 4) (controlled by the ICHX) and gas cooler pressure. It can be seen that COP decreases as the refrigerant is cooled down at the ICHX (reduction of the intermediate superheat), and the optimum gas cooler pressure tends to increase. ICHX is used to reduce the discharge temperature and reduce exergy losses at the second compression (Cecchinnato, 2009), but the decrease in heating capacity due to the rejected heat is more important than the reduction of work at compression. On the other hand, the gas cooler pressure has a bigger influence on the discharge temperature (Figure 5b) and a lower influence on COP; therefore, changing it seems a more suitable strategy in order to reduce the discharge temperature. 
When the injection-throttled valve is controlled in order to fix the superheat at the entrance of the high-pressure compressor, it has a similar effect to the case with ICHX. Heating COP decreases as the total superheat decreases, and the optimum gas cooler pressure increases (Figure 5). On the other hand, gas cooler pressure and total superheat seems to have the same influence on the discharge temperature (Figure 5d).

Although the maximum COP values are similar for both cooling systems, COP and heating capacity degradations at high refrigerant cooling are bigger using ICHX since it is removing heat from the system that could be used at the gas cooler. On the other hand, the throttling valve control at point 4 cools down the refrigerant by fluid interaction inside the circuit; thus, the reduction in the enthalpy of the refrigerant is counteract by the increase of the injected mass flow rate.

In order to compare the two methods to reduce the discharge temperature, a target temperature of $100^{\circ} \mathrm{C}$ is reached with each method, while the gas cooler pressure is kept constant (table 2). It is possible to reach target temperature with a higher COP and heating capacity by means of the throttling valve to control the total superheat instead of using an ICHX. Furthermore, the cost of the installation can be reduced by removing the ICHX.

In the case of ACC, the main compressor works between the gas cooler and evaporating pressures; hence, the discharge temperature can only be reduced by decreasing the gas cooler pressure. Nevertheless it has a limit because the temperature of the auxiliary compressor is reduced at the same time, and there is a point where the mixing temperature of both fluxes drops below $80^{\circ} \mathrm{C}$ at the entrance of the gas cooler, which is not enough to warm water up to $80{ }^{\circ} \mathrm{C}$. In table 2, it can be seen that this limit is when the discharge temperature is around $124^{\circ} \mathrm{C}$. Even in this situation, the reduction in COP is higher than in the TSCC system.

\section{CONCLUSIONS}

Transcritical systems working with $\mathrm{CO}_{2}$ are normally used for high temperature lift and high temperature applications due to their great performance in these conditions. Based on this, this work has analysed several possible alternatives in order to implement a heat pump for the production of water at $80^{\circ} \mathrm{C}$ with a temperature 
lift of $40^{\circ} \mathrm{C}$ for substitution of boilers in old heating installations in Europe using $\mathrm{CO}_{2}$ as a refrigerant. The main conclusions of the work are:

- TSCC and ACC have a similar heating COP distribution with the gas cooler and intermediate pressure, but the higher discharge temperature observed for the ACC system could limit its performance and operation range at low evaporating temperatures.

- The compressor design for both systems is significantly different; for the TSCC cycle, optimum COP is found when the displacement volume of both compressors are similar, and, for the ACC cycle, the optimum is found when the auxiliary compressor is one fourth the displacement volume of the main compressor.

- $\quad$ TSCC and ACC have an improvement of COP with respect to the single-stage $\mathrm{CO}_{2}$ cycle and twostage R134a cycle of 11 and 14 per cent respectively.

- When the evaporating temperature is $-15^{\circ} \mathrm{C}$, the discharge temperature of the ACC cycle is $133.4^{\circ} \mathrm{C}$, which can avoid the operation on the optimum point in this condition.

- The reduction of the pressure at the gas cooler has a greater effect on the reduction of the discharge temperature than on the heat rejected at ICHX with a smaller COP degradation. Heating COP is reduced when ICHX is incorporated to the system.

- In TSCC, the control of the intermediate superheat at the HP stage inlet by means of the injectionthrottling valve has less COP and heating capacity reduction than using ICHX.

- A way to reduce the discharge temperature with the ACC cycle is to decrease gas cooler pressure, even though has more limitations than the TSCC .

From this, it can be concluded that an ACC system probably is the easiest implementation of all the systems and, for moderated evaporation temperatures, could have COP similar to the other two-stage systems. TSCC is the system with higher COP and could work in a wider temperature range and condition than the ACC system. Finally, assuming that the system would work with only one compressor (the two stages are integrated in the same shell), it should be pointed out that the compressor design will play a crucial role in the final performance of this kind of system. 


\section{ACKNOWLEDGEMENTS}

This work has been developed in the 7 framework program of the European Union by the project Next Generation of Heat Pump Technologies (NEXTGHP) grant agreement 307169. The authors give thanks for the given support. Part of the work presented was carried by Miquel Pitarch-Mocholí with the financial support of the Phd scholarship from the Universitat Politècnica de València.

\section{REFERENCES}

Agrawal, N., Bhattacharyya, S., Sarkar J., 2007. Optimization of two-stage transcritical carbon dioxide heat pump cycles. International Journal of Refrigeration. 46, 180-187. doi:10.1016/i.ijthermalsci.2006.04.011

Austin, A.T., Sumathy, K., 2011. Transcritical carbon dioxide heat pump system: A review. Renewable and Sustainable Energy Reviews. 15, 4013-4029. doi:10.1016/i.rser.2011.07.021

Bowers, C., Elbel, S., Petersen, M., Hrnjak, P.S., 2013. Development of high efficiency carbon dioxide commercial heat pump water heater. International refrigeration and air conditioning conference Purdue. 19, 823-835. DOI:10.1080/10789669.2013.833543

Cecchinato, L., Corradi, M., Fornasieri, E., Zamboni, L., 2005. Carbon dioxide as refrigerant for tap water heat pumps: A comparison with the traditional solution. International Journal of Refrigeration. 28, 1250-1258. doi:10.1016/j.jijrefrig.2005.05.019

Cecchinato, L., Chiarello, M., Corradi, M., Fornasieri, E., Minetto, S., Stringari, P., Zilio, C., 2009. Thermodynamic analysis of different two-stage transcritical carbon dioxide cycles. International Journal of Refrigeration. 32, 1058-1067. doi:10.1016/.i.jirefrig.2008.10.001

Cho, H., Baek, C., Park, C., Kim, Y., 2009. Performance evaluation of a two-stage CO2 cycle with gas injection in the cooling mode operation. International Journal of Refrigeration. 32, 40-46. doi:10.1016/j.jirefrig.2008.07.008

F-Chart Software. Engineering Equation Solver (EES), Academic professional V9.433

Groll, E.A., Kim, J.-H., 2007. Review of Recent Advances toward Transcritical CO2 Cycle Technology. HVAC\&R Research. 13, 499-520. DOI:10.1080/10789669.2007.10390968

Lorentzen G., 1994. Revival of carbon dioxide as refrigerant. International Journal of Refrigeration. 17, 292300. doi:10.1016/0140-7007(94)90059-0

Lorentzen, G., Pettersen, J., 1993. A new efficient and environmentally benign system for car air conditioning. International Journal of Refrigeration. 16, 4-12. doi:10.1016/0140-7007(93)90014-Y

Pitarch, M., Navarro, E., Gonzalvez, J., Montagud, C., Corberan, J.M., 2014. Influence of water lift temperature in transcritical and subcritcal refrigerants. Conference: $\mathrm{V}$ congreso iberoamericano de ciencias y tecnicas del frio. Tarragona.

Samer S., 2008. Theoretical evaluation of trans-critical CO2 systems in supermarket refrigeration. Part I: Modeling, simulation and optimization of two system solutions. International Journal of Refrigeration. 31, 516-524. doi:10.1016/i.ijrefrig.2007.05.017 
Sarkar, J., 2012. Transcritical co2 refrigeration systems: comparison with conventional solutions and applications. International Journal of Air conditioning and refrigeration. 20, [11 pages]. DOI: 10.1142/S2010132512500174

Self, S.J., Redy, B.V., Rosen, M.S., 2013. Geothermal heat pump systems: Status review and comparison with other heating systems. Applied Energy. 101, 341-348. doi:10.1016/.apenergy.2012.01.048

Srinivasan, K., 2011. Identification of optimum inter-stage pressure for two-stage transcritical carbon dioxide refrigeration cycles. The Journal of Supercritical Fluids. 58, 26-30. doi:10.1016/i.supflu.2011.04.015

Regulation (EU) No 517/2014 of the European Parliament and of the Council of 16 April 2014 on fluorinated greenhouse gases.

Xu, X., Hwang, Y., Radermacher, R., 2011. Refrigerant injection for heat pumping/air conditioning systems: Literature review and challenges discussions. International Journal of Refrigeration. 34 402-415. doi:10.1016/j.ijrefrig.2010.09.015 


\section{LIST OF FIGURES}

Figure 1. Double-Throttling, Double-Compression, Split Cycle (TSCC) a) Scheme, b) P-h diagram.

Figure 2. Double-Throttling, Auxiliary Compressor Cycle (ACC) a) Scheme, b) P-h diagram.

Figure 3. $\mathrm{T}_{\mathrm{e}}=0^{\circ} \mathrm{C}$ : Cycle TSCC without ICHX: a) COP b) Maximum temperature of the system, entrance of gas cooler. Cycle ACC: c) COP d) Maximum temperature of the system, discharge main compressor.

Figure $4 . \mathrm{T}_{\mathrm{e}}=0^{\circ} \mathrm{C}$. COP vs displacement volume ratio for TSCC without ICHX and ACC. Gas cooler pressure are 105.7 and 106.1 bar for TSCC and ACC respectively, their optimum.

Figure 5. $\mathrm{T}_{\mathrm{e}}=-15^{\circ} \mathrm{C}$ : Cycle TSCC with ICHX: a) COP b) Temperature at the entrance of gas cooler. Cycle TSCC control at point 4: c) COP d) Temperature at the entrance of gas cooler. 